\title{
SECRETARIAL NOTES
}

The sixth ASTIN colloquium was held in Arnhem from 27th September to Ist October 1966 at the invitation of the Dutch Actuarial Society and I 10 members from 16 countries, many accompanied by their ladies, attended. A pre-colloquium reception generously arranged by the Netherlands Union of Non-Life Insurers and at which greetings were given by $\mathrm{Mr}$. $\mathrm{H}$. W. Bloemers, Governor of the Province of Gelderland provided an opportunity to meet old and new friends before the working sessions.

The formal proceedings were opened by Mr. A. W. Dek, President of the Dutch Actuarial Society, after whom, Dr. Ammeter, Chairman of ASTIN, called on the Secretary for his report. A high level of activity had been maintained in all directions, the membership having again shown a significant increase, the actual numbers on 3oth August being:-

$\begin{array}{lr}\text { Ordinary Members } & 562 \\ \text { Corporate Members } & \text { I08 } \\ \text { Special Members } & 2\end{array}$

The finances, under the control of the Treasurer, Mr. P. Thyrion, remained very sound with a balance at the bank of B. Frs. 482, 824. The substantial increase compared with the June 1965 figure did not reflect the true position because of the inclusion of a number of subscriptions for the year 1966/7 and the inclusion of the gift from the General Reinsurance Company Limited. Furthermore substantial outgoings in respect of printing the Bulletin were expected shortly. There was certainly no need to modify the subscriptions, following the increase in 1965 to B. Frs. 250 and B. Frs. 625 for Ordinary and Corporate Members respectively, but with an expected 4 parts of the Bulletin to be issued in the next 12 months, the margin could not be regarded as excessive.

The editorial duties had been undertaken by Mr. Welten who had also been heavily engaged with the organisation of the 6 th Colloquium. It is important that papers presented to colloquia are published as early as possible and for this to be done members are earnestly requested to return corrected proofs without delay. The task of the editor is not a light one and this would be one valuable way of echoing the thanks expressed to him.

Dr. Ammeter was invited to the proceedings in connection with the $75^{\text {th }}$ anniversary of the French Institute of Actuaries and presented a suitable engraved pewter jug to mark the occasion on behalf of ASTIN members.

Work was proceeding on the text book on the Mathematical Theory of Risk and it was hoped that a final draft would be completed shortly. Considerable work had also been done on the statistics made available by the Conference of European Insurance Supervisors in connection with their request for help in studies of excess provisions in non-life insurance companies.

No final decision had been reached on the use to which the generous gift by the General Reinsurance Company might be put, but there was considerable support for the suggestion that it could be used as a prize fund for outstanding contributions, particularly from younger members. 
Following this report the work of the colloquium was started by an invited address by Dr. H. Bühlmann, entitled "Experience Rating and Credibility", the title of Subject I of the colloquium, followed by a summary by Dr. T. Braakman of the 6 papers submitted under this subject. In the afternoon, under the Chairmanship of Mr. N. E. Masterson, 6 members joined in an active discussion on Subject $I$, suitably rounded off by Dr. Bühlmann.

The Organising Committee in devising the programme, had limited the subjects to two, but had provided for discussions on work discussed at earlier colloquia and of new lines of investigation. The first discussion under this heading then followed Subject I.

On Thursday, the morning session under the Chairmanship of Prof. E. Franckx opened with an invited lecture entitled "Driving with Markov programming" by Prof. dr. G. de Leve and Ir. P. J. Weeda, delivered by the latter author. After this well delivered lecture in which the authors not only solved an interesting and difficult problem but also gave us a practical application of recently developed techniques, Dr. van Klinken gave a summary of the three papers submitted under Subject 2 "Application of Methods of Operation Research and Modern Economic Theory".

In the afternoon Dr. Johansen took the chair and the Io interventions on Subject 2 showed the degree of interest of members in this field. A further discussion on other topics with 7 interventions was followed by a special session to discuss questions arising from the work being done for the European Supervisors.

The final working session on Friday morning, under the Chairmanship of Dr. Ammeter, opened with summaries of the discussions by Drs. Braakman, van Klinken and Jansen. A vigorous debate then followed after an opening by Mr. Monic on the series of articles which had appeared in the "Quarterly Letter" under the title "Is ASTIN doing well". Time being short, translations were omitted, but 7 speakers managed to express varied views on the subject. The debate was worth while, and thanks were expressed to Mr. Monic for the stimulus to self-examination, even if only to show that ASTIN has to cater for a wide spectrum of tastes from highly theoretical to the severely practical and that there was no evidence of complacency among the members.

The Chairman then expressed thanks to all those who had contributed to the undoubted success of the colloquium, the Organising Committee, the Dutch Institute of Actuaries, the Netherlands Union of Non-Life Insurers, the lecturers, the contributors of papers and to the discussions, the Chairman, Secretaries and Rapporteurs and finally to the excellent translations by Miss T. G. Gijtenbeek.

The Chairman then announced that the Committee had decided, in view of the nearness of the I8th Congress in Munich and the Colloquium to be held in Berlin following the Congress that no Colloquium be held in 1967 . However, invitations had been provisionally accepted for colloquia to be held in Poland in 1969 and in Denmark in 1970. Drs. Wanatowski and Johansen suitably acknowledge the appreciation of members for these invitations.

Following custom, Dr. Ammeter then announced that having completed his 2 years of office, Mr. N. E. Masterson had been elected to succeed him as Chairman and Mr. J. Sousselier as Vice-Chairman. Members showed their appreciation of these elections, which were appropriately acknowledged and 
the meeting closed with a standing ovation to support the tribute paid by Mr. Masterson to the outgoing Chairman.

In the evening a highly successful banquet was held at the Cafe-Restaurant Royal. On Saturday many members and their wives joined in a coach trip to the Veluwe and the IJ sselmeerpolders. 